\title{
Pollen Performance of Annona cherimola Mill. (Annonaceae) Is Affected by Temperature and Moisture Content during the Final Stages of Pollen Development
}

\author{
J. Lora and J.I. Hormaza \\ IHSM 'La Mayora' CSIC-UMA \\ 29750 Algarrobo-Costa, Málaga \\ Spain
}

\author{
M. Herrero \\ Departamento de Pomología \\ Estación Experimental de Aula Dei-CSIC \\ Zaragoza \\ Spain
}

Keywords: Annona cherimola, cherimoya, pollen, temperature, moisture content

\begin{abstract}
Cherimoya (Annona cherimola Mill.) is a subtropical fruit tree with an incipient but promising commercial production niche in subtropical climates. However, the expansion of this crop from its areas of origin has taken place without its natural pollinating agent and crop production relies heavily on hand pollination. Erratic yields are often obtained without apparent causes, and they could be related to the lack of knowledge on the biological requirements of pollen in this species. Since pollen performance in the pistil is dependent on previous pollen development in the anther, here we perform a study on the influence of temperature and water content on final pollen development stages and, as a consequence, on pollen performance in $A$. cherimola. The results show a significant influence of temperature and relative humidity on pollen performance. These results provide biological support for adequate pollen handling to optimize production in this species.
\end{abstract}

\section{INTRODUCTION}

Annona cherimola is a species of the Annonaceae, a basal Angiosperm family with 130 genera and 2,300 species, 900 of which are found in the Neotropics (Chatrou et al., 2004). Cherimoya is believed to be native from Southern Ecuador-Northern Peru (Van Damme et al., 2000) and is particularly interesting since it produces an edible fruit. Cherimoya is an incipient crop in a number of countries and is also produced at a limited commercial scale in some Latin American countries.

Cherimoya shows protogynous dichogamy (Schroeder, 1971) a characteristic common in Annonaceae (Gottsberger, 1999), with hermaphroditic flowers where female and male structures do not mature simultaneously generally preventing self-fertilization in the same flower. Moreover, flowers of the same genotype are synchronized and, consequently, transfer of pollen between different flowers of the same genotype is also hindered. The lack of overlap between male and female stages in cherimoya together with the fact that the crop was expanded without its natural pollinator agent, results in the fact that hand pollination with pollen and stamens together is a common practice for commercial production in different areas of the world (Schroeder, 1971). Environmental conditions at pollination time are very important for fruit set and erratic yields are frequent following hand pollination, indicating that differences in pollen management can play a key role in fertilization success and, consequently, yield. Thus, in this work we study final pollen development stages and the influence on this process of two variable environmental factors, temperature and water content in order to optimize hand pollination and, consequently, final production.

\section{MATERIALS AND METHODS}

The effect of temperature on pollen germination was studied during the flowering period from June to September 2005 in natural conditions in the field. Adult trees of $A$. cherimola 'Campas' located in a field cultivar collection at the EE La Mayora-CSIC, Málaga, Spain, were used in these experiments. Flowers in the female stage were collected from the field two or three times a week from June to September, at 16:00 h, 
approximately half an hour before they switch to the male stage, and carried to the laboratory to evaluate pollen germination.

The effect of temperature during the final phases of pollen development was also studied in growth chambers under controlled conditions. Flowers were collected at preanthesis at 9:00 $\mathrm{h}$ and put in $50 \mathrm{ml}$ Falcon tubes with water in growth chambers at 25, 30 and $35^{\circ} \mathrm{C}$ up to anther dehiscence. In vitro pollen germination was also evaluated at $15,25,30$ and $35^{\circ} \mathrm{C}$.

To evaluate the influence of the hydration status during final pollen development on mature pollen, pollen development and pollen germination were evaluated in flowers kept at room temperature or left in the trees under field conditions. In both treatments, three flowers were sampled at different times: at 9:00, 14:00 and 19:00 $\mathrm{h}$ in the first day and at 9:00, 14:00, 16:00 and 18:00 $\mathrm{h}$ in the second day of the flower cycle. In pollen from these flowers, moisture content and pollen germination were evaluated. Pollen germination was evaluated following the protocol of Lora et al. (2006).

\section{RESULTS AND DISCUSSION}

Average daily temperatures during the cherimoya flowering season in 2005 ranged from 20 to $29^{\circ} \mathrm{C}$ and pollen germination ranged from 27 to $78 \%$ (Fig. 1). Pollen germination showed a significant correlation (Pearson's correlation coefficient $-0.372 P=$ 0.21 ) with the average temperatures occurring one day prior to pollen shedding. Pollen germination was reduced at higher temperatures. In control temperature chambers, the highest pollen germination was obtained in pollen from flowers maintained at $25^{\circ} \mathrm{C}$ and germinated at the same temperature (Table 1). But a significant decrease in pollen germination was observed in pollen from flowers kept at 30 or $35^{\circ} \mathrm{C}$, and also on pollen germinated at 35 or $15^{\circ} \mathrm{C}$. Thus, the results obtained indicate that temperatures higher than $30^{\circ} \mathrm{C}$ result in a decrease in pollen germination whereas lower temperatures do not have a clear effect on pollen germination.

Pollen germination from flowers developed under field conditions showed a high germination from 9:00 a.m. (54\%) in the second day of the flower cycle up to anther dehiscence $(53 \%)$. A similar pattern was also observed in pollen from flowers kept at room temperature, but with the highest pollen germination (73\%) at 9:00 h the second day of the flower cycle and thereafter pollen germination decreased reaching $25 \%$ at anther dehiscence. Water content of pollen decreased more rapidly in anthers from detached flowers left at room temperature.

Our results suggest an influence of temperature and water content on pollen germination. These results are of relevance to understand the effect of environmental conditions on pollen performance and to design strategies to optimize pollen collection and hand-pollination in commercial cherimoya orchards.

\section{ACKNOWLEDGEMENTS}

Financial support for this work was provided by the Spanish Ministry of Education (Project Grants AGL2009-12621 and AGL2010-15140), INIA (RF200900010), GIE-Aragón 43, Junta de Andalucía (FEDER AGR2742), and the European Union under the INCO-DEV program (Contract 015100). J.L. was supported by a grant from Junta de Andalucía.

\section{Literature Cited}

Chatrou, L.W., Rainer, H. and Mass, P.J.M. 2004. Annonaceae. p.18-20. In: N. Smith et al. (eds.), Flowering Plants of the Neotropics, Princeton, New Jersey, USA.

Gottsberger, G. 1999. Pollination and evolution in neotropical Annonaceae. Plant Species Biol. 14:143-152.

Lora, J., Oteyza, M.A.P., Fuentetaja, P. and Hormaza, J.I. 2006. Low temperature storage and in vitro germination of cherimoya (Annona cherimola Mill.) pollen. Sci. Hort. 108:91-94.

Schroeder, C.A. 1971. Pollination of cherimoya. California Avocado Society 44:119-122. 
Van Damme, P., Van Damme, V. and Schedelman, X. 2000. Ecology and cropping of cherimoya (Annona cherimola Mill.) in Latin America. New data from Ecuador. Fruits $55: 195-256$.

\section{Tables}

Table 1. Effect of temperature during flower development and during germination on cherimoya 'Campas' pollen germination (\%). Means followed by the same letter in a column are not significantly different $(\mathrm{p} \leq 0.05)$ by Duncan's multiple range test.

\begin{tabular}{lccc}
\hline Temperature of pollen & \multicolumn{3}{c}{ Temperature of flower development $\left({ }^{\circ} \mathrm{C}\right)$} \\
\cline { 2 - 4 } germination $\left({ }^{\circ} \mathrm{C}\right)$ & 25 & 30 & 35 \\
\hline 15 & $46 \mathrm{ab}$ & $22 \mathrm{~cd}$ & $10 \mathrm{c}$ \\
25 & $64 \mathrm{a}$ & $55 \mathrm{ab}$ & $35 \mathrm{bc}$ \\
30 & $53 \mathrm{ab}$ & $55 \mathrm{ab}$ & \\
35 & $34 \mathrm{bc}$ & & $8 \mathrm{c}$ \\
\hline
\end{tabular}




\section{Figures}

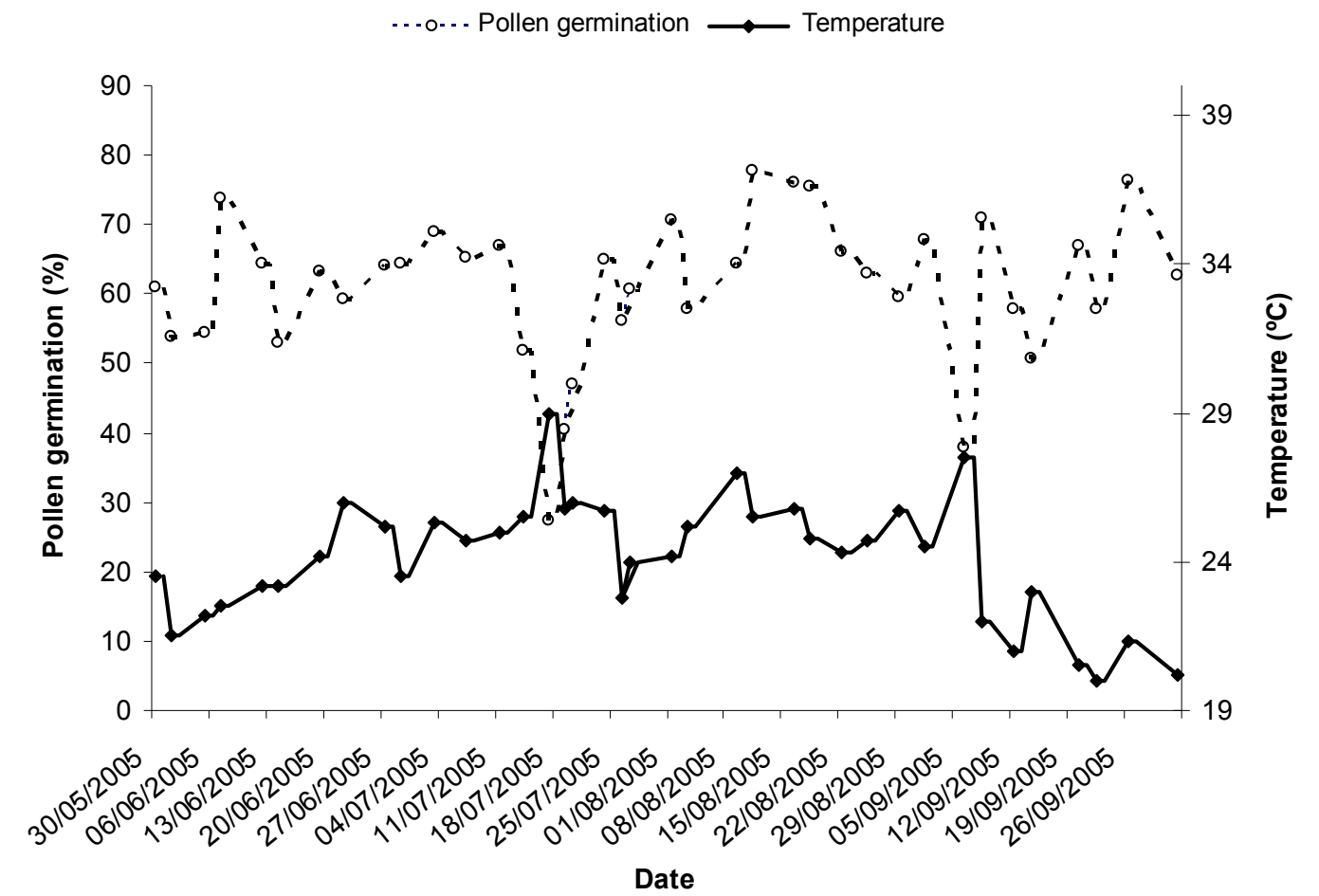

Fig. 1. Pollen germination of cherimoya 'Campas' and average temperatures during the flowering period from June to September. 